\title{
Case Study: DRM-protected Music Interoperability and e-Innovation
}

\section{Citation}

Urs Gasser \& John Palfrey, Case Study: DRM-protected Music Interoperability and e-Innovation, Berkman Center Publication Series No. 2007-9 (2007).

\section{Published Version}

http://cyber.law.harvard.edu/publications/2007/

DRM_Protected_Music_Interoperability_and_elnnovation

\section{Permanent link}

http://nrs.harvard.edu/urn-3:HUL.InstRepos:2794938

\section{Terms of Use}

This article was downloaded from Harvard University's DASH repository, and is made available under the terms and conditions applicable to Other Posted Material, as set forth at http:// nrs.harvard.edu/urn-3:HUL.InstRepos:dash.current.terms-of-use\#LAA

\section{Share Your Story}

The Harvard community has made this article openly available.

Please share how this access benefits you. Submit a story.

Accessibility 
BREAKING DOWN DIGITAL BARRIERS

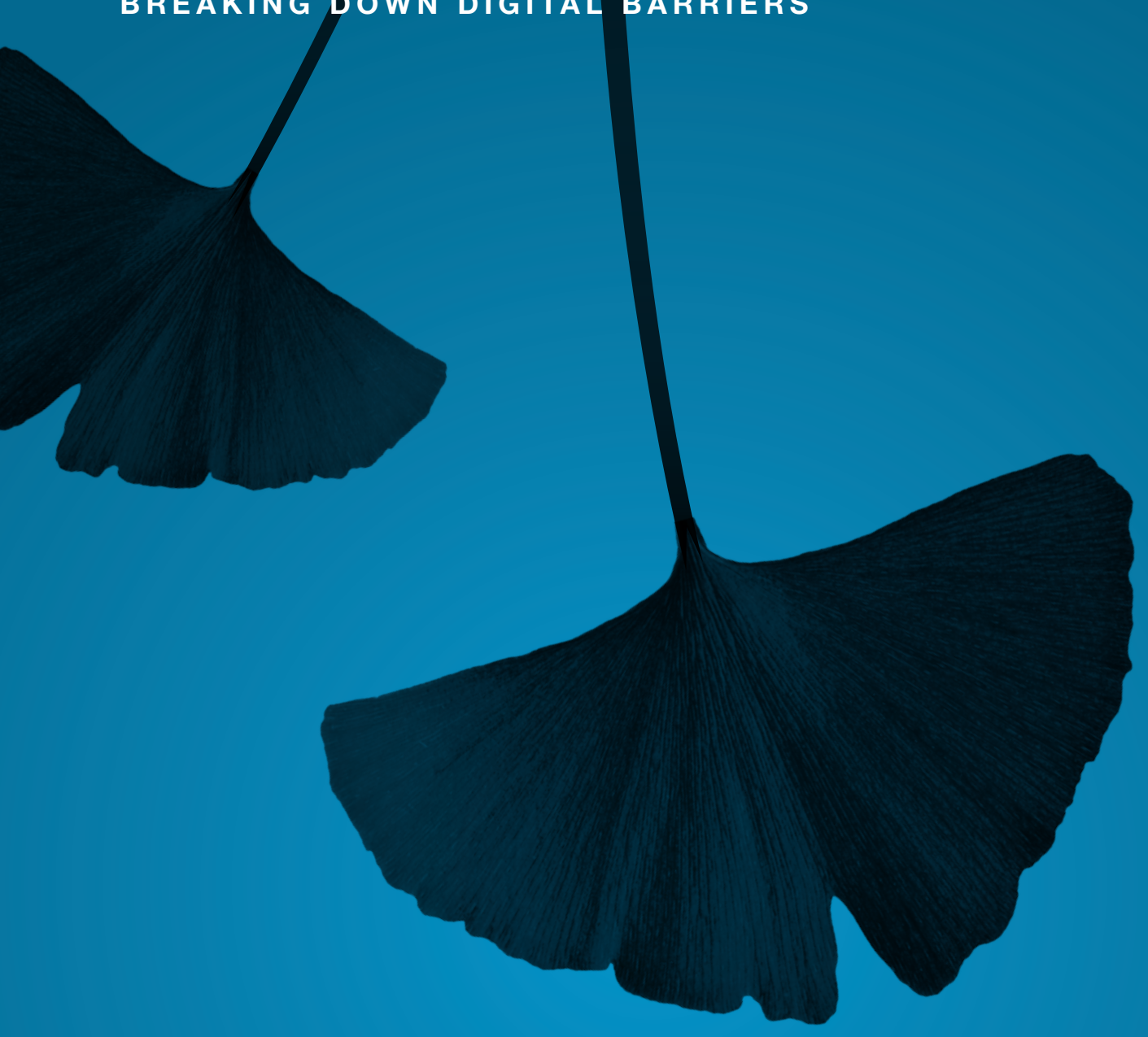

CASE STUDY

DRM-protected Music

Interoperability and elnnovation

by Urs Gasser and John Palfrey

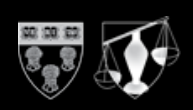

Berkman

The Berkman Center for Internet \& Society at Harvard Law School
Research Center

for Information Law

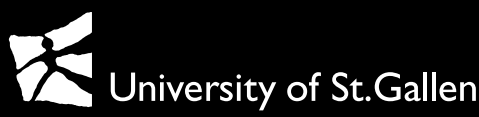

Sponsored by:

Microsoft 


\title{
CASE STUDY \\ DRM-protected Music Interoperability and elnnovation
}

Urs Gasser and John Palfrey

\author{
Berkman Publication Series, November 2007 \\ http://cyber.law.harvard.edu/interop
}

The Berkman Center for Internet \& Society, Harvard University Research Center for Information Law, University of St. Gallen Sponsored by Microsoft ${ }^{\oplus}$

This work is licensed under the Creative Commons

Attribution-Noncommercial-Share Alike 3.0 United States License.

To view a copy of this license, visit http://creativecommons.org/licenses/by-nc-sa/3.0/us/ 


\section{ABSTRACT}

This report - representing one of three case studies that are part of a transatlantic research project aimed at exploring the potential relation between ICT Interoperability and eInnovation - examines issues surrounding DRM interoperability within the context of music content. Recognizing that interoperability will likely be defined differently by different stakeholders, we begin by establishing a rough, holistic working definition of interoperability and then assess the implementation of DRM in the music content market and associated problems with regard to interoperability. We then go on to explore the technological, market, and legal environments in their relation to and impact upon the achievement of interoperable DRM systems. In part 2, we analyze potential benefits and drawbacks of an interoperable DRM environment for the music content market. We then evaluate both private and public-initiated approaches towards the accomplishment of interoperability using a series of qualitative benchmarks. Lastly, we conclude by summing up the merits and demerits of the various approaches. Our findings lead us to surmise that normative considerations weigh in favor of greater interoperability in general. The challenge of determining the optimal level of interoperability and the best approach for attaining it, however, points toward consideration of a number of complex factors. We conclude that the best way to determine the optimal level of interoperability and means of accomplishing it is to rely upon economic-based assessments on a case-by-case basis. 


\section{TABLE OF CONTENTS}

About this Report

Introduction

1 State of Play: DRM Music Interoperability 4

1.1 What is DRM Interoperability? 4

1.2 DRM Interoperability and Music Distribution 7

$\begin{array}{ll}\text { 1.2.1 Offline distribution } & 7\end{array}$

1.2.2 Online distribution 8

1.3 Forces at play: Some drivers and inhibitors 12

1.3.1 Complex technology 12

1.3.2 Dynamic market incentives 16

1.3.3 Conflicting influences of law 19

2 Assessing DRM Music Interoperability 24

2.1 Possible benefits 24

2.1.1 Competition and innovation 24

2.1.2 Autonomy, choice, and flexibility 27

2.1.3 Access, diversity, and openness 28

2.2 Possible drawbacks $\quad 29$

$\begin{array}{ll}2.2 .1 \text { Security } & 30\end{array}$

$\begin{array}{ll}\text { 2.2.2 Privacy } & 31\end{array}$

2.2.3 Accessibility 32

2.3 Conclusion 33 
3 Approaches towards DRM Music Interoperability $\quad 36$

3.1 Basic Framework 36

$\begin{array}{ll}3.1 .1 \text { Overview } & 36\end{array}$

$\begin{array}{ll}\text { 3.1.2 Mapping approaches } & 37\end{array}$

3.1.3 Benchmarks 38

3.2 Evaluating selected approaches towards DRM music interoperability 39

3.2.1 Selected approaches by private actors 39

3.2.1.1 Reverse engineering 39

3.2.1.2 IP Licensing 41

3.2.1.3 Open Standards 44

3.2.2 Selected regulation-based approaches 48

3.2.2.1 Mandating Standards 48

3.2.2.2 Disclosure of interoperability information 51

3.2.2.3 Transparency rules, labeling requirements 53

3.2.3 Conclusion 55

4 Summary 58 


\section{ABOUT THIS REPORT}

This report represents one of three larger case studies on interoperability in information and communication technologies (ICT) as part of a transatlantic research initiative between the Berkman Center for Internet \& Society at Harvard Law School and the Research Center for Information Law at the University of St. Gallen (Switzerland). The research initiative, supported by Microsoft, Inc., seeks to address four core questions: First, what is an appropriate understanding of "interoperability" in important areas of digital technology? Second, is there a positive relationship between higher levels of interoperability in ICTs and innovation beyond anecdotal evidence, grounded in focused analytical work? Third, what are possible approaches to achieve ICT interoperability, ranging from IP licensing to open standards, and what are their respective benefits and drawbacks? Fourth, based on the answers to the first three questions, what conclusions can be drawn for policymakers and other stakeholders when it comes to ICT interoperability? Naturally, different research designs could be used to explore these questions. The principal investigators of the present research initiative decided to answer the four core questions in concrete rather than abstract terms by working with three larger, exploratory case studies from which more general conclusions - in the sense of "lessons learned" - might be drawn. This report summarizes the findings with regard to the case study on DRM-protected Music Interoperability and should be read against the backdrop of the four larger research questions previously mentioned. Consequently, this study does not aim to discuss DRM in general nor does it seek to provide a comprehensive discussion of interoperability as such. Rather, we have chosen to examine DRM-protected music due to its value as a significant microcosm within the digital environment from which beneficial insights might be gained with regard to the guiding research interest behind this project.

The design of the research initiative, which has produced a series of publications including a Policy White Paper, is certainly shaped by the investigators' underlying attitudes towards interoperability which can be summarized as follows: Like many observers of the ICT space, the authors of this study are inclined to think that interoperability in the ICT space (as elsewhere) is desirable. As a policy matter, the contributors to this report believe that innovation, consumer choice, and competition are sound policy goals. To the extent 
that some forms of interoperability are likely to contribute to these ends, the authors will argue that interoperability should be promoted. Much of the exercise undertaken in this report, however, is to adopt a skeptical stance toward these positions and to ascertain whether the evidence supports them. 


\section{INTRODUCTION}

Françoise M. bought Alain Souchon's "J'veux du Live," a CD distributed by EMI France. The CD played on her home entertainment system, but not on the CD player in her Renault Clio. As it turned out, the copy protection scheme on the $\mathrm{CD}$ rendered it impossible to play the $\mathrm{CD}$ on certain devices, including car radios. Françoise M. and a French consumer protection organization filed a lawsuit against EMI with the Tribunal de Grande Instance de Nanterre. That court ruled that a CD that could not be played on all players restricts consumers and must therefore be considered a defective product. Accordingly, the court held that the music fan had the right to get her money back.

In summer 2004, RealNetworks added a new feature called "Harmony" to its RealPlayer. Harmony allowed users of the RealPlayer Music Store to play their songs on iPods from Apple. This action on the part of RealNetworks frustrated Apple's music protection scheme, FairPlay, that, among other things, prevents songs bought from other online music stores to be played on an iPod. In response, Apple threatened (but did not file) a lawsuit against RealNeworks and soon upgraded its software to disable RealPlayer's converting functionality.

The two examples in the preceding paragraphs - taken from the perspective of a consumer and competitor respectively - tell stories about the use of a certain type of technology known as digital rights management (DRM) systems. In the digital media realm, such systems are used by right-holders to control the access to and use of music or other forms of digital content. DRM technology essentially allows right-holders to set and enforce rules about what users can and cannot do with digital content distributed either over the Internet or on physical media such as CDs or DVDs. The initial rationale for DRM was mainly to stop large-scale copyright infringement over peer-to-peer networks. More recently, however, alternative justifications such as price-discrimination and platform innovation have been identified. ${ }^{1}$ 
Traditional DRM schemes regulate the interoperation between digital products and services. ${ }^{2}$ In order to serve its purposes (most importantly, to regulate access to digital content and its redistribution, but also to allow price discrimination, depending on the particular business model), it is deliberately designed to create a certain degree of incompatibility. Depending on the perspective and context, the resulting level of interoperability may be perceived as a positive or negative result. In the case of Françoise M., it is rather straightforward that the lack of interoperability led to a negative consumer experience. In the second example, the lack of interoperability between competing online music stores and players is clearly intended by Apple, which uses DRM to create a strong tie between its popular portable music player (iPod) and the iTunes Store. Viewed from the competitor's perspective, in contrast, a certain degree of interoperability between an alternative online music service and Apple's iPod would be desirable, as Real's Harmony illustrates.

This paper addresses the issue of DRM music interoperability in greater detail. The first part of the case study starts with a brief working definition of DRM interoperability and provides an overview of the current state of play of DRM-protected music. The emphasis of this section is on the degree of DRM interoperability that characterizes online music distribution. We then identify key factors and forces that affect the current level of interoperability in the DRM ecosystem. In this context, we also explore the divergent and often dynamic incentive structures among different players and their effects on the development and proliferation of interoperable DRM systems. The second part of the paper discusses possible benefits and drawbacks of DRM interoperability, thereby focusing on the relationship between DRM interoperability and innovation. Finally, in part three, we map and assess different approaches towards DRM interoperability, including market-based approaches and possible governmental interventions, according to specified benchmarks. Part four summarizes and concludes that a blended private-sector approach with secondary, reinforcing actions by regulators is likely to be the most promising strategy towards increasing and sustainable DRM interoperability. 


\section{STATE OF PLAY: DRM MUSIC INTEROPERABILITY}

\subsection{What is DRM Interoperability?}

The definitions and interpretations of the term "DRM interoperability" are manifold and heterogeneous. The EU High Level Group on Digital Rights Management, for example, defines the term as follows:

In the context of DRM the term interoperability encompasses consistent functioning of the overall system including security and access, such that the system is able "mutually to use" information in the form of usage rules, content and technical measures "in all the ways in which they are intended to function”. This would apply even when content from different interoperable services is used and when such content is used on different interoperable devices. For the consumer, interoperability means he can choose different devices and use them with different services. For the content producer or content aggregator interoperability means he is not locked in to one distribution channel that forms a gatekeeper to the marketplace. For the device and ICT developer, interoperability means that his products can be used with different content services - and that a gatekeeper does not form around a specific DRM technology. ${ }^{3}$ 
Heileman and Jamkhedkar, to take an example from the scholarly literature on the subject, discuss the term DRM interoperability in their survey paper as follows:

It seems that everyone has a notion of what interoperability means, which generally revolves around the idea of "things" working together. A slightly more formal definition related to technology is: "The ability of one technology to interact with another technology in order to implement some useful functionality". It is possible to make nearly any two DRM technologies work together in a manner that satisfies this definition. Specifically, by building translation services, it is often possible to make one DRM regime work with a different DRM regime. At the current stage of development of DRM markets, this approach to interoperability makes sense. ... However, in order to facilitate the continued development of DRM markets, more detailed notions of interoperability of DRM technologies must be developed. In this sense, the real issue is not interoperability per se, but rather the level of interoperability that allows better DRM solutions to be created. ${ }^{4}$

Koenen et al., for instance, flesh out the concept of DRM interoperability by distinguishing among three types of interoperability:

Full format interoperability expects that the interchange representation of the digital content can be consistently processed based on agreement between all participants in the value chain. ... Full format interoperability usually entails robustness criteria and a certification regime to establish trustworthiness and security of conformant implementations. ...

Connected interoperability builds on the expectation that consumers will have online access, and relies upon online services, some of them possibly transformative or capable of complex negotiation, to solve interoperability problems in a transparent way. While different parties may do things in different ways, translations or bridges exist between the ways different parties perform DRM functions, and that mutually trusted parties can perform these translations transparently, as long as devices are connected at least some of the time. ...

Configuration-driven interoperability assumes that system components ("tools", possibly from different vendors) can be downloaded and/or configured in real-time at e.g. the consumer's device or software application. This allows consumer systems to effectively "acquire" functionality on demand in order to accommodate new formats, protocols, and so on.... ${ }^{5}$ 
The few examples provided in the previous paragraph illustrate the diversity of approaches aimed at defining and conceptualizing the term "DRM interoperability." An extensive review of various proposals confirms that a common definition of the concept has not emerged. Arguably, the difficulty to agree on a common definition has to do with the multi-layered architecture of DRM schemes and their interactions with components such as hardware, software, and data. In order to be useful in the context of this policy paper, a working definition of DRM interoperability should share a number of characteristics. First, it is important that the definition is broad enough to embrace both process and architecture-oriented concepts of DRM interoperability. ${ }^{6}$ Second, and related to the first aspect, the working definition should not predetermine the ways in which a desired level of interoperability must be achieved. In fact, we will examine rather distinct approaches to achieve interoperability in a later part of this paper, and all approaches to DRM interoperability should fit under the working definition. Third, interoperability as a concept is not a binary characteristic: different degrees of interoperability exist along a spectrum. ${ }^{7}$ Fourth, interoperability is often context-specific: In different circumstances it means different things to different stakeholders (such as consumers/ users, vendors, right-holders, etc.).

Against this backdrop, we use the term DRM interoperability not in the narrow, nor in the strictly technical sense, but as the perceived notion of proper functioning of the relevant elements of two or more entities that facilitates access to and use of digital content. Often, of course, the content is digital entertainment goods, but not always. At the core of this definition is the relative ability of different systems, applications, or components - usually provided by multiple vendors - to work together in a way that is satisfactory to the relevant users of the system, application, or component. 
A relatively high degree of DRM interoperability according to this definition would mean different things to different stakeholders, for example:

- DRM interoperability from the user's perspective means that she can flexibly choose among different services that offer DRM-protected content, which in turn can be used with different applications or on different devices.

- From the angle of a content provider, DRM interoperability means that content and rights can be "cleared" once and distributed over the most efficient distribution channel, without being locked into a gatekeeperlike distribution channel.

- From the content distributor's perspective, DRM interoperability ensures that its technology choice doesn't affect the utility of its service to users, as the delivered content might be played by any application and device.

- Interoperability for the vendor means that her products work with different services, or (more generally) that one system's component can be replaced by a component from another vendor.

In the next section, we will briefly analyze to what extent the current DRM music ecosystem is - or is not - characterized by high degrees of interoperability.

\subsection{DRM Interoperability and Music Distribution}

\subsubsection{Offline distribution}

In November 2005, Sony BMG Music Entertainment announced that it had instructed retailers to remove any unsold audio CDs that were copy-protected by so-called "rootkit" software from their shelves. This recall followed after an intense public controversy concerning Sony BMG's integration of a copy protection measure on CDs representing over 100 titles. The copy protection involved software that automatically installed on a consumer's computer (after she accepted the EULA) when she tried to play the CD, making the computer vulnerable to virus attacks, worms, and other forms of malware. A number of lawsuits, including class actions in New York and California, were filed and later settled.

At the root of the Sony BMG rootkit story is the right-holders' attempt to protect copyrighted music distributed on CDs by technological means. While 
CDs were initially sold without any DRM protection schemes in place, in 2002 and 2003 the industry started to implement copy control technologies on CDs as a response to the widespread availability of CD burners, which enabled users to copy digital sound recordings onto blank CDs at low marginal costs and with excellent quality.

The Sony BMG rootkit example and the above-mentioned story of Françoise M. illustrate that copy control technology on CDs has had a series of (occasionally unintended) consequences. First, because many protected CDs departed from the published standards for CD Audio, they did not work on certain devices such as DVD players, CD-ROM drives, portable players, and car CD players, causing a type of interoperability problem that was previously unknown. Second, some copy-protected CDs - as in the case of Sony BMG rootkit - interfered with a computer's proper functioning by causing system crashes and creating security risks for these PCs. Third, the copy controls prevented users not only from making illegal copies but also from exercising traditional fair use rights, even though it did allow them to make a few backup CD-R copies and transfer the music to MP3 players using Microsoft or Sony DRM.

Facing interoperability problems, security risks, legal risk exposure, and consumer complaints, the right-holders started reconsidering the use of copyprotection schemes on CDs, and major labels, including EMI, recently announced that they would abstain from using such technology on CDs in certain markets (especially in the U.S. and UK). ${ }^{8}$ In other parts of the world, however, copy-protection technology on CDs is still employed, arguably resulting in a CD music ecosystem with limited interoperability.

\subsubsection{Online distribution}

Online distribution channels accounted for about ten percent of total music sales in the full year of 2006, up from $5.5 \%$ in $2005 .{ }^{9}$ The record companies' 
digital music sales reached USD 2 billion in 2006 and continues to grow. ${ }^{10}$ The music has been distributed over nearly 500 online music services in 40 countries, run by major content providers, third parties/intermediaries, ISPs, content portals, and mobile content suppliers. New online business models include digital downloads (e.g. iTunes Store) or subscriptions services (e.g. Rhapsody, Napster, and eMusic), including portable versions (e.g. Napster To Go).

At present, the large majority of the offerings licensed by the big record labels uses DRM schemes to regulate the various aspects of digital music usage, including, for instance, the type and number of devices on which the downloaded or streamed song can be played, the number of CDs on which it may be burned, or the possibilities of transferring the file to portable devices such as cell phones or MP3 players. ${ }^{11}$ In essence, four main DRM systems have been developed and used in the area of digital music, the first two currently being the most important ones:

- FairPlay is the DRM system created by Apple and used by the iPod, iTunes, and the leading online music service iTunes Store.

- Windows Media DRM, consisting of a number of components, is Microsoft's DRM audio and video scheme for the Windows Media platform.

- OpenMG is the DRM music scheme that was used by Sony until it abandoned its online music store in August 2007.

- HelixDRM by RealNetworks is a protection scheme for audio and video formats that has been used by a range of music and video services, including Rhapsody.

As mentioned, DRM systems also regulate the extent to which digital products and services interoperate. In the case of DRM-protected online music, 
many observers - including lawmakers ${ }^{12}$ and government agencies - have diagnosed relatively low degrees of interoperability. In fact, several major players in the online music space have decided to keep their DRM ecosystems and platforms closed.

Most prominently, Apple, as the owner of the leading iTunes Store, has refused to license its FairPlay DRM system to its competitors, including online music stores and device manufacturers (with the exception of licenses for Motorola mobile devices). As a result, its products and music services only support DRM-protected content if it is encoded with Apple's closed DRM system. For example, music purchased from the iTunes Store and protected by its FairPlay technology can only be played on iPods, certain Motorola cell phones, and Apple's own iPhone, but not on other portable music players such as Microsoft's Zune. Audio files in unprotected formats, in contrast, can be imported. Thus, it is possible to rip songs from an unprotected CD and to import them into the iTunes library and play them on the iPod.

In contrast to Apple, Microsoft's initial DRM strategy has been to license its Windows Media DRM system to other market players as part of the socalled "PlaysForSure initiative." License holders include online music stores and device manufacturers. Among the online stores that sell digital content protected by Windows Media DRM are Napster, DirectSong, MTV's URGE and Unbox. Hardware device vendors supporting Windows Media DRM wrapped content include, among others, Motorola, SanDisk, Philips and Toshiba. Among these players and their services and devices there is a high degree of interoperability, but not vis-à-vis other important market forces, most notably market leader Apple. Further, Microsoft recently revisited its approach to interoperability with regard to Windows Media DRM and its Windows Media Player. In particular, Microsoft uses a variant of the Windows Media DRM for its portable player Zune and the corresponding online store Zune Marketplace. Consequently, music that is compatible with Microsoft's PlaysForSure initiative (e.g. music bought in Napster) may not be used on its Zune player. Zune software can import unprotected audio files in formats such as WMA, MP3, AAC and the like. 
Similar to Apple's and, more recently, Microsoft's approach, Sony established an exclusive linkage between its Connect Store and the Sony players. In contrast to Microsoft and Apple, Sony also owns a music catalogue; Sony's market significance in online music distribution is, however, comparatively low. RealNetwork's Helix DRM, the fourth DRM system in use in the market for digital music distribution, has been partly made available to third parties, such as portable devices from SanDisk; however, RealNetworks announced in spring 2007 that it would no longer sell its technology, but will continue to support existing customers, including Rhapsody. ${ }^{13}$

The examples provided so far reveal an online music ecosystem where DRM interoperability issues are among its central problems. However, several developments should be noted where the DRM interoperability challenge has been avoided. First, a subscription-based service called eMusic allows permanent music downloads as DRM-free MP3s. Its music catalog consists of over two million songs from independent labels. Second, two of the four major record labels have moved tentatively away from DRM. EMI recently announced that it would license its music catalog DRM-free and at higher sound quality to online music stores in return for a premium. Following this announcement, iTunes Store has offered DRM-free tracks from EMI at a slightly higher price (\$1.29 per song instead of \$0.99). ${ }^{14}$ Continuing the trend, Universal Music, the record label with the largest market share, has temporarily made a portion of its library available for DRM-free sale on a variety of online music stores. ${ }^{15}$ It remains to be seen how these arrangements will develop over time and whether the other labels will follow suite. Abandoning DRM altogether would obviously sidestep the DRM interoperability issue entirely with respect to online music distribution. Amazon.com, a long-anticipated entrant to the online music market that launched a beta version of its music store in the US in September 2007, is an interesting case in this context. ${ }^{16}$ All songs on Amazon MP3, including songs from EMI, Universal, and independent labels, are available as DRM-free downloads. 
Despite this tentative movement away from DRM, most market observers would agree that the current online music ecosystem is still characterized by a relatively low degree of interoperability as defined in this study and as far as music licensed by the major labels is concerned. The assessment of this state of play requires an overview of the benefits and drawbacks of different levels of interoperability. This is the theme of part 2 of this paper. In the next section, however, we will first discuss some of the key forces at play to gain a better understanding of what has shaped the current state and may influence the future level of DRM interoperability.

\subsection{Forces at play: Some drivers and inhibitors}

Digital music distribution is a complex system. Technically, it requires the implementation and functional interplay of advanced digital technologies. Additionally, it consists of a relatively complicated network of market actors whose incentive structures are sometimes aligned and other times diametrically opposed. Apart from market factors, a complex set of legal norms governs the digital music distribution system, including copyright law, consumer protection law, anti-trust law, and the like. Dynamic communities of like-minded users, as well as user expectations and preferences, also play an increasingly important role. These four characteristics have to be taken into account if one seeks to identify factors and forces that shape the state of play in the digital music ecosystem. In this paper, however, we focus on three issues: First, we address important aspects that illustrate the technical challenges associated with achieving high levels of interoperability among DRM systems. Second, we outline the incentive structure of different stakeholders in the online music space that might point toward different levels of DRM interoperability. Finally, we address the interaction between the legal system and levels of interoperability.

\subsubsection{Complex technology}

A look at a basic DRM reference model with key domains such as

- Packaging, rules generation, and modification;

- Value chain management and licensing services;

- Consumption services;

- Trust management services; 
- Security and protected platform services;

- The corresponding functionalities illustrate the technological complexity behind DRM schemes as applied to digital content. ${ }^{17}$

Against this backdrop, it does not come as a surprise that various theoretical approaches to DRM interoperability have been proposed. Process-oriented approaches ask how different pieces of the functionality can be implemented among actors when different DRM technologies are used..$^{18}$ In contrast, architecture-oriented approaches conceptualize interoperability from the perspective of a layered DRM framework. ${ }^{19}$

From the practical perspective, much of the debate in the recent past has centered on ways to achieve a common understanding of usage rights. DRM systems, as mentioned above, express and enforce usage rights related to a specific digital file. DRM systems describe authorized usage (i.e., usage policies like, "this song may only be played on 5 authorized computers") through meta-data that is associated with the content, and is expressed through what is called in the industry a Rights Expression Language (REL).$^{20}$ In order to successfully manage protected content, it is therefore necessary that the different technical elements "understand" the same language. Take, for example, a band that distributes a DRM-protected music track over an online music platform specializing in independent music with the intent that it be playable on a user's PC and mobile phone. If several parties along the value chain use DRM systems from different vendors, all involved DRM systems must understand the same "language" in order to give effect to the instructions

See, e.g., Koenen et al., supra note 5, pp. 5-9.

For approaches along the process line see, e.g., Koenen et al., supra note 5 (exploring three ways to achieve interoperability: full format interoperability, connected interoperability, configuration-driven interoperability); Andreas U. Schmidt, Omid Tafreschi, and Ruben Wolf, Interoperability Challenges for DRM Systems, http://andreas.schmidt.novalyst.de/docs/Interoperability_Challenges_for_DRM_Systems.pdf (connected interoperability); Reihaneh Safavi-Naini, Nicholas Paul Sheppard, Takeyuki Uehara, Import/Export in Digital Rights Management, in: Proceedings of the Third ACM Workshop on Digital Rights Management, pp. 13-26, Washington D.C., October 2003 (connected interoperability/translation architectures). 
(usage rights) attached to the file. One way to ensure that usage rights will be understood and respected is to establish a uniform REL, and in fact several market players have argued that the development of a uniform REL is a first step toward enabling DRM interoperability. In this context, two initiatives have shaped the current DRM landscape:

- eXtensible Rights Markup Language (XrML): XrML, developed by ContentGuard (a company originally founded by Microsoft and Xerox), describes rights, fees, conditions, message integrity and authentication and is based on the "extensible markup language" (XML). Some industry players have regarded XrML as the basis for a universal REL as mentioned above. For example, XrML has been used by the Moving Pictures Expert Group (MPEG) as the basis for one part (Part 5) of the MPEG21 standard, which later became an international standard. The MPEG$21 / 5$ is designed for the licensing of digital audio and video content in particular. A version of XrML is also used in Microsoft's DRM systems.

- Open Digital Rights Language (ODRL): In digital media, one of XrMLıs main competitors is ODRL. It evolved from an open process, is managed by an open initiative led by its founder Renato Iannella. ODRL can be seen as the open-source, license-free equivalent to commercial XrML. ${ }^{21}$ In fact, ODRL is in many respects similar to MPEG $21 / 5 .^{22}$ It is successfully used in the area of mobile devices and has been adopted by the Open Mobile Alliance (OMA) as the REL for its DRM specification.

Despite initial successes, observers doubt whether XrML or ODRL are likely to become an accepted standard for expressing usage rights in DRM systems any time soon. ${ }^{23}$ First, each approach reportedly has its own problems. ODRL, for instance, is facing a legal challenge, as ContentGuard, the company that developed XrML, claims that its patents on XrML cover any rights expression language, including ODRL. XrML, in contrast, struggles with long-term sustainability in the marketplace: Two of its most important derivatives - Microsoft's version of XrML and the REL forming part of the MPEG-21 standard - remain incompatible with each other and there are no 
signs that Microsoft will change that situation, according to commentators. ${ }^{24}$ Second, the initiatives have to contend with a growing number of proprietary DRM systems of competitors (and consortia). ${ }^{25}$ More fundamentally, some stakeholders argue that a single universal REL is not necessary for achieving a common understanding of usage rights. Rather, different DRM systems only need to be able to interpret one another's usage restrictions.

Along these lines, the Coral Consortium is developing specifications that will allow different DRM systems to "talk to one another." The consortium was formed in 2004 by a cross-industry group of seven major media and technology companies to promote DRM interoperability. Its basic approach is "to separate content interoperability from choice of DRM technology by developing and standardizing a set of specifications focused on interoperability between different DRM technologies rather than specifying DRM technologies" and to create an "interoperability layer." ${ }^{26}$ Since its launch, the consortium has released several interoperability specifications and, for example, has successfully established "out of the box" interoperability with OMA DRM and Microsoft Windows Media DRM, among others. ${ }^{27}$ Despite these successes, the initiative is generally not believed to have fully succeeded - not due to technical shortcomings but rather due to a lack of support by important market players, particularly Apple. Furthermore, the Moebius Forum aims at establishing interoperability between different DRM systems by enabling their conversion into MPEG-21, an ISO-standardized REL. ${ }^{28}$ The forum was founded in 2006 under the auspices of CISAC (The International Confederation of Authors and Composers Societies) and arguably will face challenges similar to those of the Coral Consortium.

To sum up, DRM systems are technically complex, and interoperability among DRM systems from different vendors is a difficult issue to address. 
From a technical perspective, different approaches have been proposed for the achievement of interoperability. In practice, much attention has been paid to the question of how to implement rights expression languages for the expression of usage policies and which need to be understood by the various technical elements of the DRM system if the system wants to successfully facilitate usage rights transactions and interdict unauthorized uses. We have outlined attempts aimed at creating a uniform REL. Other approaches towards DRM interoperability do not envision a uniform REL, but seek to define a set of specifications in order to create mutual "understanding" of usage restrictions among different DRM systems. Each of these approaches has certain merits and demerits, and it is currently uncertain whether one of the approaches will prevail. Lastly, it is important to understand that a common understanding of usage rights is a necessary, but not wholly sufficient condition for DRM interoperability. The interoperation of elements of the DRM model such as, for instance, identity and authentication services must also be addressed and present further challenges.

\subsubsection{Dynamic market incentives}

Until recently, DRM interoperability at the application layer had largely been left to market forces - and several stakeholders argue that this more or less laissez faire approach should continue. In this section, we will take a look at the market forces at play by discussing some of the economic incentives regarding the creation of DRM music interoperability, assuming that DRM providers could overcome technological challenges and achieve high degrees of interoperability among their systems (e.g. by way of DRM licensing) if they have incentives to do so. The starting place for the discussion is the observation that both consumer surveys and common sense suggest that at least consumers have a strong preference for interoperable music systems and applications. ${ }^{29}$ Why, then are we still facing a DRM interoperability problem as outlined above? At least part of the answer lies in the rather heterogeneous and dynamic incentive structure among key participants in the online music 
market. ${ }^{30}$ Linking back to the examples provided above, Apple's and Microsoft's DRM interoperability approaches are illustrative.

As noted, Apple as the market leader in the online music business has a very restrictive interoperability policy as far as its DRM system FairPlay is concerned. Reportedly, it has licensed its DRM system only in a single case (Motorola mobile devices) and has responded negatively to technological attempts by competitors seeking to establish higher degrees of interoperability. Observers have suggested that such an approach aimed at restricting interoperability is a key element of Apple's business model. First, it has been argued that the exclusive link between iTunes and iPod creates significant entry barriers for portable players and, to some extent, for music download services. Second, the restrictive approach is believed to have leveraged Apple's strong position in the market for portable music devices into a similar position among music downloading services. Finally, Apple’s strategy arguably allows for greater price discrimination vis-à-vis a consumer base that is tightly linked to both the music store and the music player and at the same time increases consumers' switching costs. ${ }^{31}$ However, Apple officials have contested whether this analysis is an adequate account of its business motives. After being heavily criticized by different stakeholders, especially consumers' organizations, Apple's CEO and co-founder Steve Jobs denied in a recent statement that the lack of interoperability has been part of Apple's business strategy. Instead, he argued that it was a mere consequence of the record labels' requirement that Apple provide effective DRM protection, while Apple in turn could only 
guarantee the required level of protection if its DRM system was not licensed to other parties. Jobs went on to ask record labels to completely abolish the requirement of DRM protection. ${ }^{32}$ Whether intentionally or not, non-interoperability has proven to be a very successful business strategy for Apple to date, providing strong incentives against high levels of DRM interoperability.

We have already mentioned Microsoft's DRM media interoperability policy. Viewed from the user's perspective, the second most important player's interoperability strategy has not been very consistent.

- As noted, Microsoft has followed a relatively open licensing strategy for its Windows Media DRM, enabling interoperability among services and devices. Arguably, the PlaysForSure initiative has served several business goals, such as increasing the distribution and importance of the Windows Media Player jukebox (including the Windows Media DRM), increasing the Internet audience on their MSN Network service, and facilitating Micosoft's entry into the digital living room business. Reportedly, these were also the guiding objectives when Microsoft launched its MSN Music Store in October $2004 .^{33}$

- In contrast, Microsoft did not opt for DRM interoperability when introducing the Zune audio player and the Zune Marketplace online store, respectively, but rather designed a closed ecosystem like Apple's iPodiTunes model. In addition, Microsoft limited DRM interoperability within its own DRM ecosystem: MSN Music Store closed its virtual doors, and songs previously bought on it cannot be played on Zune. ${ }^{34}$

Market observers have attributed Microsoft's shift in its DRM interoperability strategy to the low market performance of the MSN Music Store vis-à-vis the successful Apple iTunes Store. 
These two examples - others could be added - illustrate at least three interesting phenomena that shape the DRM interoperability landscape. First, DRM interoperability strategies might vary even within one (relatively heterogeneous) group of stakeholders. Second, there are situations in which key players in the online music market have economic disincentives to promote DRM interoperability, despite strong user preferences to the contrary. The desire to control secondary markets, or to increase switching costs for consumers, to name just two examples, might motivate business strategies that lead to non-interoperable environments. Finally, a single player's attitudes towards interoperability may change over a relatively short period of time. These three observations represent complicating factors for assessing the promises and limitations of a market-driven approach to DRM music interoperability.

\subsubsection{Conflicting influences of law}

The legal system, too, shapes the DRM music interoperability playing- field. On the one hand, general laws - like consumer protection laws - might apply to issues relevant to DRM interoperability. On the other hand, we have seen the emergence of specific laws aimed at addressing the DRM interoperability challenge. The recently enacted French interoperability provision (discussed in section 3.2.2.2) is a case-in-point in this context. Some aspects of the legal system foster DRM music interoperability, others discourage it. In the following paragraphs, we will use this rough distinction for analytical purposes only, acknowledging that laws (e.g., patent law) can be used in more than one way and for various purposes.

A first set of rules that can be used against high levels of DRM interoperability is patent protection of DRM technology. Depending on the scope of a particular patent, a patent holder may be able to control the design of devices or applications intended to work with files protected by its DRM technology. Under such a scenario, patent law can be used to preserve a closed DRM ecosystem, or to make the creation of an interoperable DRM framework more expensive by extracting licensing fees. The issue of patent protection of DRM technologies or certain components of it, respectively, has recently been raised in the context of ODRL's rights expression language. ContentGuard, the owner of several patents related to the XrML REL (see above), argues that its patents do not just apply to the specific characteristics of XrML, but to any implementation of a rights expression language, including ODRL's version. Against this backdrop, the MPEG Licensing Administration claims that every 
service provider or device manufacturer that implements the Open Mobile Alliance (OMA) DRM 1.0, which includes ODRL as part of its specification, is obliged to pay a levy to MPEG-LA consortium members. It remains to be seen if and how this move influences the creation of an interoperable DRM ecosystem in the mobile entertainment industry. ${ }^{35}$

Another complex interplay between DRM interoperability and the law relates to legal frameworks that govern technological protection measures. Such frameworks - known as anti-circumvention legislation and introduced by the 1996 WIPO Internet Treaties - provide an additional layer of protection for digital content by prohibiting the "hacking" of DRM-systems and technologies alike and banning the trafficking in so-called circumvention devices. ${ }^{36} \mathrm{In}$ the interoperability context, the question arises as to what extent such provisions allow reverse engineering of a DRM-system. The EU Copyright Directive (EUCD) of 2001, for instance, does not answer this question. Recital 54 of the EUCD only mentions that interoperability "should be encouraged," without providing further guidance. However, good arguments have been put forward that the anti-circumvention framework itself (mainly Art. 6 of the EUCD) allows the design of interoperable systems by outlawing only trafficking in such circumvention devices that are (inter alia) primarily designed and marketed for the circumvention of effective technological protection measures (TPM). In other words, "hacking" a certain DRM system might be legal under the EUCD if it does not compromise the limitation of use of a DRM-ed work. ${ }^{37}$ However, the national implementations of the EUCD vary significantly and courts have not yet resolved this issue. ${ }^{38}$ In addition, reverse MPEG LA software patent claims, available at http://www.indicare.org/tiki-read_article. php?articleld=90. tent: Moving Forward Towards a Best Practice Model, 17 Fordham Intell. Prop., Media \& Ent. L.J. 39 (2006) for a discussion of the international legal framework with regard to the protection of technical protection measures.

In this context, it is noteworthy that at least one Italian Court has ruled that the use of modified chips aimed at restoring the full functionality of a Sony PlayStation (incl. its ability to read all discs from all markets despite region coding) is not illegal under the EUCD's anti-circumvention provisions. See Andrea Glorioso, EUCD Wiki, available at http://eucd.wizards-of-os.org/index.php/Italy\#Anti-Circumvention_Provisions. 
engineering is usually outlawed under the applicable terms of service. ${ }^{39}$ The situation under the U.S. Digital Millennium Copyright Act (DMCA), the EUCD's counterpart, is somewhat different in the sense that Sec. 1201(f) sets forth a specific, but narrow reverse engineering provision. The exception allows reverse engineering of computer programs if the acting party lawfully obtains the program, seeks permission from the copyright holder, uses the results only for creating an interoperable computer program and does not publish them. Most importantly in the context of this paper, the resulting software may only interoperate with the reverse engineered software and not with data designed for that software. Sec. 1201(f) applies, in other words, only to software-to-software interoperability and does not allow reverse engineering to enable interoperation between software and the DRM-ed content itself (software-to-data interoperability). ${ }^{40}$

In cases where intellectual property rights are exercised to keep DRM systems closed and the refusal to interoperate is used as a lever for anti-competitive behavior, competition law might level the playing field. Competition law may become particularly relevant in cases where a company with a dominant market position refuses to license its DRM technology, attempting to dominate an important component of a layer and to use that dominance to frustrate competition in other components (vertical leveraging). ${ }^{41}$ To date, however, there is no case law at the EU level where competition law has been applied to the DRM interoperability problem. But there are important cases (IMS Health and Magill, but also the anti-trust actions against Microsoft) illustrating how competition law - at least in exceptional circumstances - can give 
the need for interoperability more weight than the IP claims of a dominant player. While IMS Health and Magill are in part based on an assessment of whether the refusal to give access to a product or service prevents the emergence of a new product, in its Microsoft decision the European Commission raised the question of whether the refusal to license reduces the incentive to innovate throughout the industry. In its recent judgment, the European Court of First Instance largely confirmed the Commission's decision and stated that the conditions for exceptional circumstances were fulfilled in the case before the court. At the same time, the court clarified that the Commission's previous decision should not be read as if there were a new evaluation test to be introduced that balances incentives to innovate of the dominant company against those of competitors. ${ }^{42}$ At the member state level, the question of refusal to license came up for discussion in 2004, when VirginMedia attempted to gain access to iTunes' FairPlay system by using French competition law. The French competition authority, however, ruled in favor of Apple, partly because it considered the (actual and potential) market for music players at the time to be sufficiently competitive. ${ }^{43}$

Another important area of law that has an impact on the degree of DRM interoperability is consumer protection. European consumer protection authorities in particular have addressed DRM interoperability issues within the last few years. The Norwegian Consumer Ombudsman, for instance, has been very critical of Apple's iTunes Store interoperability policy in response to a complaint by the consumer council. The Ombudsman argues that "iTunes' DRM is an unreasonable technical term of use, in so far as it prevents purchasers of music files at iTunes from using other MP3 players than iPods," and that the technical terms violate the Norwegian act relating to the control of marketing and contract terms and conditions. ${ }^{44}$ The case is still ongoing. org/tiki-read_article.php?articleld=150. For an economic analysis, see François Lévêque, Is Online Music Locked in by Leveraging?, September 2006, available at http://papers. ssrn.com/sol3/papers.cfm?abstract_id=951893. For an analysis of the antitrust allegations against Apple, see also Nicola F. Sharpe \& Olufunmilayo B. Arewa, Is Apple Playing Fair? Navigating the iPod FairPlay DRM Controversy, 5 Nw. J. Tech. \& Intell. Prop 2, 2007, p. 331 et seq. 
A French court, to take another example, fined EMI Music France for selling CDs with DRM protection schemes that would not play on car radios and computers. EMI was found to have violated consumer protection law because it did not appropriately inform consumers of these restrictions. The court obliged EMI to label its CDs with the text: "Attention - cannot be listened to on all players or car radios." ${ }^{45}$ At the EU level, finally, a recent proposal by the European Consumers' Organisation suggests the inclusion of DRM-related provisions in the Unfair Contract Directive. This proposal reflects the idea that consumer protection authorities - like the Norwegian Ombudsman should also be able to intervene against unfair consumer contract terms if the terms are "code" rather than "law-based."

The preceding paragraphs illustrate that the current state of DRM music interoperability has not entirely been left to the evolutionary forces of the market. Instead, the present level of interoperability in digital music is also the result of multi-faceted interactions with the legal system, which on the one hand enables businesses to establish and maintain closed DRM systems via contract, copyright and anti-circumvention laws, but on the other hand has also been used to seek a more interoperable DRM ecosystem (consumer protection laws, competition law). The finding that the legal system pulls music DRM interoperability in conflicting directions must be taken into account when considering future approaches to DRM interoperability in section 3. 


\section{ASSESSING DRM MUSIC INTEROPERABILITY}

In the previous section, we have mapped the current state of DRM music interoperability and the technological, economic, and legal forces of influence. In this section, we outline some of the merits and demerits generally associated with high levels of DRM interoperability. Particular attention will be paid to the question of to what extent higher degrees of DRM interoperability are likely to foster innovation in e-environments. In this context, it is important to recall the scope of this study: We focus on interoperability among DRM systems and do not discuss the pros and cons of using such systems in the music ecosystem at all. Consequently, we do not explore the range of innovations at the content layer (e.g. music mashups, sampling, parodies, etc.) that might be possible in a DRM-free music space.

\subsection{Possible benefits}

\subsubsection{Competition and innovation}

Interoperable DRM systems allow consumers of digital music to transfer their music collection from one device or service to another, i.e., to switch between different vendors. Conversely, it is more difficult to change platforms in an ecosystem of vertically integrated and non-interoperable DRM systems; in this scenario, users are likely to stick to the products that support one particular DRM system. It has thus been argued that enhanced DRM interoperability would increase competition among different vendors in the digital music space, and competition, in turn, not only reduces prices but also sets 
incentives for product and service innovation. ${ }^{47}$ Additionally, higher levels of DRM interoperability would not only increase actual, but also potential competition by reducing market-entry barriers for new players.

A high level of DRM interoperability is likely to spur innovation not only by reducing lock-in effects and lowering entry barriers, but also by increasing user demand. Policy reports and industry representatives suggest that the usage restrictions associated with low levels of DRM incompatibility and the lack of transparency frustrate users and hamper consumer confidence, which in turn might depress the growth of the online music market. ${ }^{48}$ Conversely, higher levels of DRM interoperability might lead to a greater consumer base and thus induce companies to enter the online music market with innovative products and services or motivate incumbent players to improve their market position via product differentiation (e.g. a wider variety of playback devices, such as in-home networks, jukeboxes, portable players, etc.).

In contrast, it has also been argued that low levels of interoperability may set incentives to innovate by promising higher or even monopoly profits to successful participants. ${ }^{49}$ According to this argument, innovators would be more likely to incur the risk and expense of developing an innovation if they expect to make higher profits due to a closed, non-interoperable DRM system. Innovative activity would not only be encouraged by competition in the market, i.e., competition between components inside an interoperable DRM ecosystem, but also by competition for the market, i.e., competition

See also the arguments of Bomsel \& Geffroy, supra note 30, p. 45 that DRM incompatibility may represent a form of "moral hazard," resulting in a failure to maximize welfare. For a discussion of potentially detrimental effects on innovation if intellectual property rights are used principally as strategic weapons which arguably is facilitated in the age of new technologies, see: Olufunmilayo B. Arewa, Strategic Behaviors and Competition, available at http://papers.ssrn.com/sol3/papers.cfm?abstract_id =586483. 
between different non-interoperable DRM standards ("standards race"). ${ }^{50}$ In this scenario, competition may exist in the form of "creative destruction" among "temporary monopolists" that may come to replace one another by introducing entirely new ways of doing business (so-called Schumpeterian rivalry) ${ }^{51}$ According to this view, if a product or service enters the market that is substantially better than the market leader's offer, it will succeed and replace it ("leapfrog competition"). Even the proponents of Schumpeterian competition in the DRM music market, however, acknowledge that "this [form of] competition may create some hiccups and difficulties for interoperability as it goes on," but argue that the "innovation benefits are worth it." ${ }^{52}$ Critics, in contrast, go a step further and doubt whether the suggested development will take place vis-à-vis the platform switching costs as well as the (indirect) network effects within the closed DRM ecosystem that might prevent potential competitors from succeeding and consolidating the market leader's dominant position. $^{53}$

See, e.g., Nicolas Economides, Desirability of Compatibility in the Absence of Network Externalities, 79 Am. Econ. Rev. 1165, 1989 (1989) where the author explains how "[i] $\mathrm{n}$ an assymmetric setting a firm can sometimes introduce a new incompatible product attempting to establish a new industry "standard," and as a consequence establish itself , at least in perception, as the leader of the industry."

Specifically, it has been argued that in the market for digital music a non-interoperable vertically integrated ecosystem (Apple's iTunes system) was apparently needed to develop enough momentum to create a market for online distribution, as previous standardization efforts (such as the Secure Digital Music Initiative) did not succeed in enabling a sustainable and successful business model.

Prepared Statement of Raymond Gifford (The Progress \& Freedom Foundation) at the Hearing before the Subcommittee on Courts, the Internet, and Intellectual Property of the Committee on the Judiciary House of Representatives, 109th Congress, First Session, April 5, 2005, available at http://judiciary.house.gov/media/pdfs/ printers/109th/20389.pdf, p. 12.

See also, Bomsel \& Geffroy, supra note 30, p. 44 ("The impact of the incompatibility of DRMs on consumers is not unanimously considered negative, as it may result in a price decrease: if there are no network effects, incompatible vertically integrated systems face more elastic demand than compatible components .... However, con-sumer surplus may not be superior to cases where systems are compatible. Indeed, compatibility in-creases variety, enabling consumers to mix and match . . . . However, in the case of incompatibility, consumers remain free to accept or refuse each distributor's offer. This rule mostly applies to dedicated networks similar to broadcasting.") (citations omitted). For a broad overview of the economics of networks, see: Joseph Farrell \& Paul Klemperer, Coordination and Lock-in: Competition with Switching Costs and Networks Effects, 2007 (available at: paulklemperer.org). 
For another wrinkle on this issue, assume there is a current market leader that has pursued a closed DRM interoperability approach, and that market leader is forced to open up its platform - for instance as a result of an antitrust intervention. Even in such a scenario, innovation may not result. The dominant player likely developed its innovation with a view to appropriating the (monopoly) profits of its investment; if these profits diminish due to an enforced opening of its DRM ecosystem, other potential innovators might be less inclined to develop and introduce new products and services, since they have to expect a similar pattern to occur in the future. ${ }^{54}$ Alternatively, new players may engage in leapfrog innovation, but will try to extract higher monopoly profits once they have come up with an innovative product since they know, based on market observation, that such a situation may be short-lived; or they might innovate in at least a partly interoperable fashion to stave off external (i.e., antitrust) intervention.

Another complication arises from the observation that the success of innovative activities in networked markets depends on users' expectations regarding their market acceptance. Only if consumers expect an innovative product or service to become generally accepted will they switch from the old to new platforms. Of course, there are several possible criteria that might form these expectations, such as a company's reputations, marketing efforts, financial strength, or product pre-announcements. ${ }^{55}$

\subsubsection{Autonomy, choice, and flexibility}

While it remains contested what level of DRM interoperability will increase available options in the future by creating the proper incentives for firms to innovate, there is little controversy that the current state of low-level interoperability in the online music market impairs certain stakeholders' ability to chose freely among music services and MP3 devices. The next paragraphs look into the autonomy, choice, and flexibility of users on the one hand and content providers on the other. 
In the current DRM interoperability debate, the reduction of user choice ranks among the most frequently mentioned negative effects associated with the current state of affairs. If DRM systems and applications are not interoperable, as the argument goes, users cannot freely choose among competitive and efficient options with regard to components that may be tested, mixed, and matched for specific purposes. This is the case if, for instance, the user seeks to join one online store (e.g. Napster), but is prevented from doing so because her portable music device (e.g. iPod) doesn't allow her to play the songs bought on the competitor's platform. The possibility of overcoming the restrictions imposed by the non-interoperable DRM regimes does not constitute an efficient option for consumers. While the use of a tool that strips the music of DRM protection is likely to qualify as an illegal act of circumvention, other suggested ways to override the lack of interoperability ${ }^{56}$ - like burning a $\mathrm{CD}$ with the songs purchased on one store and re-importing it into the library of another platform provider - is costly, cumbersome and may reduce the sound quality of the purchased music. A high degree of DRM music interoperability, in contrast, gives users choice, flexibility, and convenience. ${ }^{57}$

Low levels of interoperability also affect other stakeholders' freedom to make choices. Content providers in particular are constrained by non-interoperable DRM systems of media distributors where they restrict the business models that may be supported. In this way, flexibility with regard to business models is decreased and the markets that content providers can reach are ultimately narrowed. Furthermore, content providers may at least in theory run the risk of being locked into a gatekeeper-like distribution channel vis-à-vis a dominant online music distributor. Again, higher levels of DRM interoperability tend to enhance choice and flexibility.

\subsubsection{Access, diversity, and openness}

From a societal perspective, the main concern about the current low degree of DRM music interoperability is that we run the risk of failing to redeem the promise of the new technologies. ${ }^{58}$ As noted above, several observers have argued that a continued lack of interoperability could frustrate consumers 
and ultimately slow down the development of digital content. It is generally acknowledged that online distribution creates efficiency gains by drastically reducing transaction costs, a feature that in turn leads to greater access to music at lower prices. Consequently, to constrain the future growth of online music distribution would also mean to leave in place access barriers that new technology would enable us to remove today.

If users do not embrace digital distribution due to usage restrictions resulting from non-interoperable platforms, niche markets will likely be underserved by content providers. Insofar as niche markets are an opportunity for a larger and more diverse set of musicians to reach their audience (in the Web 2.0 jargon: to serve the "the long tail"), low levels of DRM interoperability may result in a negative long-term impact on cultural diversity, especially if alternative means of content distribution (such as P2P file-sharing) are coming under pressure at the same time.

An open ICT ecosystem, properly developed and maintained, creates efficiency gains by public and private sector actors through increased competition, access, and control. There is also a strong general argument that an open ICT environment fosters innovation and growth. ${ }^{59}$ While interoperability is also possible within a closed system, it is clearly a condition sine qua non for an open ICT ecosystem. The role and contours of an interoperability framework within an open ICT system have been described elsewhere in greater detail. ${ }^{60}$ For our purposes, it suffices to note that DRM interoperability would be one element that might contribute to the building of such an open environment with the advantages mentioned above.

\subsection{Possible drawbacks}

The previous paragraphs have highlighted the possible benefits of a digital music ecosystem with high levels of interoperability. However, the contested debate about the right degree of DRM interoperability - and the best way to achieve it - makes it clear that interoperability is not unanimously perceived as a positive feature. Rather, several observers and market players have pointed out that a higher level of DRM interoperability comes with costs. Three 
main arguments against DRM interoperability have been made. First, it is argued that increased interoperability might compromise security. Second, higher levels of DRM interoperability could entail greater privacy issues than "segmented" DRM systems. Third, content providers with a strong interest in content protection might be less likely to license their content in light of the aforementioned security concerns, leading to a diminished universe of content available online.

\subsubsection{Security}

Among the controversial issues is whether it is possible to achieve higher degrees of DRM interoperability without compromising security of DRM protection schemes. ${ }^{61}$ In essence, two "threat models" have been portrayed.

- More players, greater security risks: Higher degrees of DRM interoperability require wider dissemination of sensitive information related to the DRM protection scheme among a greater number of market participants, including application providers or vendors of mobile music devices. Generally, a growing number of parties having access to sensitive information increases the risk of leakage, especially in cases where the incentive structures among the players aren't necessarily perfectly aligned. Such leakage has occurred repeatedly with DRM in the video area, first with CSS in first-generation DVDs (where a key was leaked from a Xing software decoder) and more recently with AACS for HD-DVDs (where a key was leaked from WinDVD).

- Increased vulnerability in case of attacks: Experts agree and anecdotal evidence confirms that there is no such thing as an absolutely secure, bullet-proof DRM system. Indeed, most if not all DRM protection schemes in the music market have already been hacked - including protection technologies by Apple and Microsoft. In an interoperable DRM ecosystem, according to this argument, the impact of one single "hack" would be far greater than in a world of DRM silos. Under such a scenario, a single leak has the potential to compromise not only one of several distribution channels, but the distribution of all interoperably DRM-ed music. In addition (and tying it to the first threat model), it has been 
argued that any leakage (or "hack") could be much more difficult to fix than in a world of different DRM systems, as the concerted action of a multitude of stakeholders would be required. ${ }^{62}$

The threat models have not gone uncontested. With regard to the first concern ("more players, more leakage"), it can be argued that the law provides means to reduce these risks, not only in terms of general statutes but also in the form of confidentiality provisions in licensing agreements and corresponding penalty clauses in case of leakage, or the like. On the other hand, contracts are only as strong as the contracting parties; once critical information has been leaked, such as the key to the DVD encryption system CSS that was revealed due to a poorly secured software DVD player by Xing, the ability to sue one's chagrined partner is small comfort. In addition, projects such as Microsoft's PlaysForSure initiative provide at least anecdotal evidence that DRM interoperability among multiple players does not necessarily lead to a less secure online music distribution environment. ${ }^{63}$

\subsubsection{Privacy}

According to some observers, an interoperable DRM regime for online music content could also present extensive privacy issues. DRM systems in the music space are often aimed at keeping track of actions taken on the part of users with regard to digital music files - above all, the number of copies made. Other DRM systems such as pay-per-use systems must report back to the content owner regarding the consumer's use of the music content. As critics have pointed out, DRM systems therefore hold the potential to enable the monitoring of individual consumption habits on the part of content owners. ${ }^{64}$ If DRM systems track usage data according to an interoperable standard, anyone who knows or is able to discover the standard may be able to gain access to it. Thus, SonyBMG would not only receive information concerning a particular consumer's usage habits with regard to SonyBMG content, but might also be able to discover that consumer's habits with regard 
to other labels' content as well. Depending on the scenario, even interested parties other than content owners (e.g. marketing firms, etc.) might be able to monitor the consumer's behavior.

Privacy concerns voiced by advocates of closed DRM systems are not universally accepted. On the one hand, it remains unclear as to how realistic the sketched scenario is in which various stakeholders along the value chain could access user information. At a glance, one can imagine that access to collected data could be restricted by technical, organizational, or legal means, much in the same way that an interoperable mobile phone system, for instance, does not entail that all players inevitably gain access to the location data of their respective customers. In other words, the particular approach to DRM interoperability will be decisive as to whether privacy concerns are amplified when moving from a low to a high level of DRM interoperability. Furthermore, some contend that the privacy problems are a result of the use of technological protection measures in the first place and have much less to do with the interoperability question at hand. ${ }^{65}$

\subsubsection{Accessibility}

As noted in the introduction, there is also an argument that high levels of DRM interoperability will impair the widespread accessibility of content the very goal it would be designed to achieve. If content owners perceive an interoperable DRM framework as entailing less security for their content, they may be unwilling to license their content unless the distributor allays security concerns with its own guarantee. ${ }^{66}$ Additionally, patent protection relating to DRM technology may render licensing terms too costly for those who wish to implement it (rather than stick to a [cheaper] non-interoperable solution) ${ }^{67}$ Critics argue, however, that perfect protection has so far not been 
a prerequisite of successful, DRM-based business models. Enforcement of usage restrictions via DRM (along with the legal protection of DRM schemes) seems to be sufficient if it deters enough to shape the behavior of the majority of users. ${ }^{68}$ Furthermore, there is a trend among content providers to conceptualize DRM systems not as measures against piracy, but as enablers for price-discrimination or as "accounting tools." ${ }^{69}$ It is hard to see how an interoperable DRM system would conflict with these functionalities. Finally, nothing seems to suggest that the content industry has withdrawn from licensing content to the participants of the PlaysForSure initiative when they aimed to create an interoperable DRM microenvironment.

\subsection{Conclusion}

Conventional economic analysis suggests with regard to innovation that both benefits and costs are associated with different levels of DRM interoperability. Against this backdrop and without empirical evidence regarding the relation between DRM interoperability and innovation in the online music market, it would be problematic to conclude in general terms that a higher level of DRM interoperability necessarily leads to more innovation in the online music space. In view of the complex interrelations among the market structure, legal landscape, and incentives of different stakeholders, we conclude instead that there is need for a case-by-case economic analysis of the particular DRM interoperability issues up for discussion - analogous to the types of analyses used in competition law cases. ${ }^{70}$ However, we have argued in the preceding paragraphs that additional normative arguments may tip the balance in general terms towards higher degrees of interoperability.

First, a qualitative analysis strongly suggests - in line with other policy reports - that a high level of DRM interoperability increases autonomy, choice, and the flexibility of users first and foremost, but also of other stakeholders in the online music market such as content providers. Second, there is a link between DRM interoperability and access to music. Insofar as a low level of Is Online Music Locked in by Leveraging?, September 2006, available at http://papers. ssrn.com/sol3/papers.cfm?abstract_id=951893. 
interoperability constrains the future growth of online music distribution as both industry organizations and policy think tanks argue, new technology or market arrangements could surmount existing barriers. Third, high levels of interoperability tend to contribute to the emergence of a diverse information environment. The same applies to the online music space, since greater DRM interoperability may increase the market players' incentives to serve niche markets. Finally, as previous research has pointed out DRM interoperability is a prerequisite for the creation of a comprehensive interoperability framework as a central building block of an open ICT framework that results in efficiency gains, fosters innovation, and results in the growth of the ICT market in general.

The discussions in the preceding sections suggest the acknowledgement of DRM interoperability as a public policy goal. While an economic analysis results in a "non liquet," important values of a democratic society (such as choice, access, and diversity) call for a high level of DRM interoperability. The possible drawbacks of an interoperable DRM ecosystem, in our view, do not outweigh its benefits. As noted, there exists no empirical and (if, at all) only little anecdotal evidence that higher levels of DRM interoperability will compromise security and user privacy. Second, many of the concerns can be dealt with at the conceptual level - e.g. as a matter of interoperability design, or by implementing organizational and legal safeguards. Third, some of the drawbacks are more closely related to the concept and use of DRM as such rather than to the degree of interoperability. Finally, the technically most powerful argument, the negative impact of increased DRM interoperability on security, becomes less persuasive in an environment in which DRM is used less and less to prevent piracy than to enable innovative forms of content distribution and service accounting. 


\section{APPROACHES TOWARDS DRM MUSIC INTEROPERABILITY}

\subsection{Basic Framework}

\subsubsection{Overview}

DRM music interoperability can be achieved in various ways, and, in fact, several approaches have already been used in practice with the aim of establishing a higher degree of DRM interoperability. In very broad strokes, one might distinguish among the following approaches and "tools":

- Unilateral Design. This occurs when a technology company designs its products or services in a way that interoperability is specifically a feature. Sun Microsystem's DReaM project, aimed at providing an interoperable DRM architecture by implementing standardized interfaces and processes, is an illustration of this type of approach.

- Reverse engineering. In the case of reverse engineering, as noted above, a given DRM system is taken apart in order to learn how it operates and build an interoperable system that unilaterally supports the competitors DRM system. An example of this was RealNetworks' Harmony software, discussed above.

- Licensing. Here, DRM interoperability is achieved by granting the contracting party access to the DRM technology and the relevant technical 
specification, including the rights associated with its use. One widely licensed technology is Windows Media DRM.

- Technical collaboration. Technical collaboration tends to overlap with licensing. One example of an ongoing collaboration between industry partners is a deal struck between Microsoft and Nokia in February 2005 .

- Standards. In the DRM context we have seen evidence of the development and implementation of various forms of market-based standards aimed at fostering interoperability between systems and applications. Among these standards is ODRL as a Rights Expression Language, discussed above. Standards in different areas have also arisen through the efforts of various industry groups and formal standards organizations.

- Regulatory Approaches. Governments can use different means to contribute to an interoperable DRM ecosystem. While certain approaches are widely contested (e.g. mandating standards, disclosure of interoperability information), others seem to be less controversial (e.g. public procurement, providing frameworks for cooperation). To date, probably the most far-reaching legislative approach to DRM interoperability has been taken by France (see below), where companies can be forced to disclose interoperability information to competitors.

\subsubsection{Mapping approaches}

The approaches outlined in the previous section, can be mapped along different dimensions. For the purpose of our study, we differentiate between private and public actors on the one hand and unilateral (or "dominant") versus collaborative strategies on the other hand. A possible map of frequently discussed approaches to DRM interoperability, viewed from a policy perspective, might look as follows: 


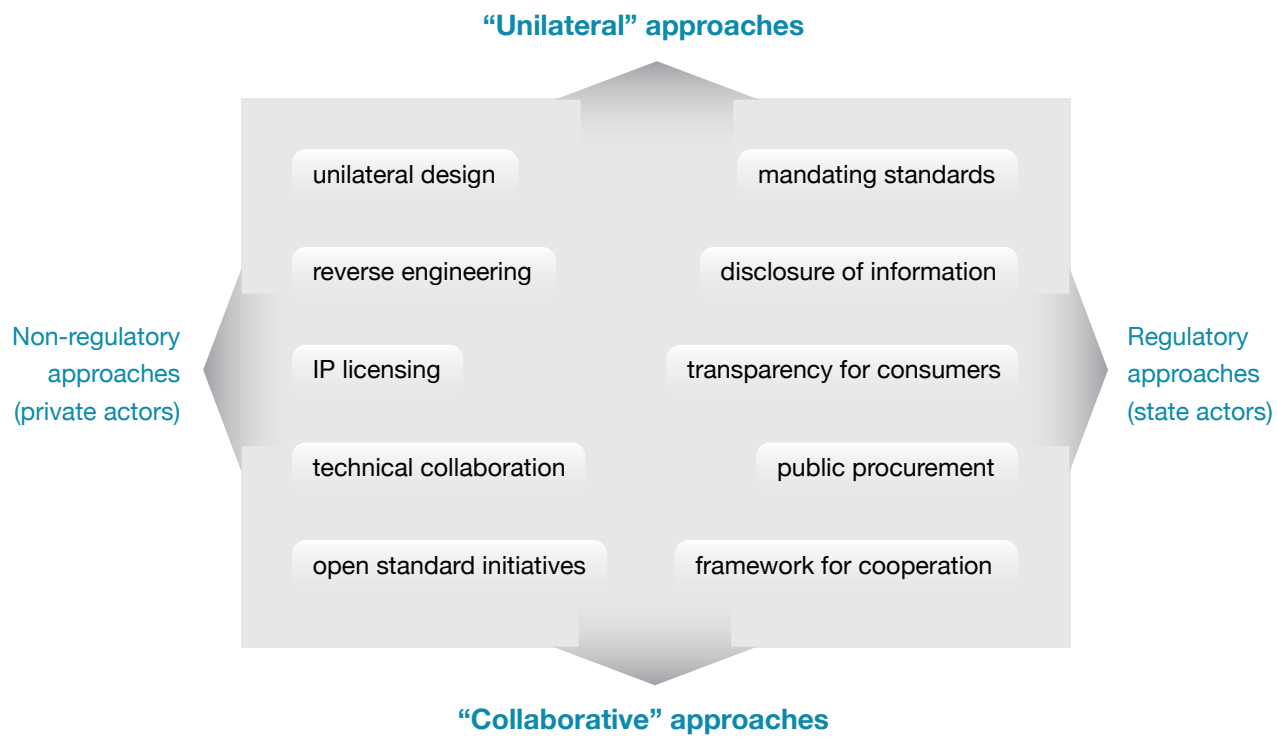

\subsubsection{Benchmarks}

The next section seeks to describe selected approaches to DRM interoperability in some greater detail and to evaluate the various means by which higher degrees of interoperability can be achieved. Such an assessment begs the question of relevant benchmarks. Given the research project to which this case study seeks to contribute, we suggest the following five criteria.

- Permeability. This criterion describes the ability of a given approach to interoperability to take into account important factual (ex ante) circumstances that characterize the ecosystem in which it seeks to operate. Such characteristics are, for example, the market's maturity, product and service maturity, state of technological development, the features of existing and emerging business models, consumer needs, etc.

- Effectiveness. Different approaches to DRM interoperability are likely to result in different degrees of interoperability achieved and maintained over time.

- Cost efficiency. As previously discussed, achieving and maintaining a certain level of interoperability comes with costs. We use the term cost efficiency here as an indicator of the level of costs imposed on affected players for a given degree of interoperability. 
- Flexibility. This criterion refers to the (bi-directional) interaction between a certain approach and ex post changes in the relevant ecosystem (i.e., the online music market) in general and to technological development in particular.

- Stimulating power. We use this fifth criterion to indicate to what degree a particular approach to DRM interoperability tends to enhance competition (e.g. by lowering entry barriers) and foster innovation (e.g. by amplifying or creating incentives).

Most of the proposed benchmarks would require a detailed case-by-case analysis if applied to one of the approaches mapped in the previous section. The "stimulating power" of IP licensing on potential market entrants, for instance, heavily depends on the terms and conditions of the license as well as the structure of the licensing fee (e.g. up-front investment or "per unit" charge). Despite this caveat, we will use the criteria in the next section to flag at least some initial projections with regard to potential strength and weaknesses of the selected approaches.

\subsection{Evaluating selected approaches towards DRM music interoperability}

\subsubsection{Selected approaches by private actors}

\subsubsection{Reverse engineering}

In the context of DRM music interoperability, we distinguish between two types of reverse engineering:

- First, an approach that aims to equip a digital file with a certain DRM technology, and thus allows it to enter a closed ecosystem of products or services that support (only) the reverse-engineered DRM system; thereby, users of the reverse-engineered system are provided with an additional source of content ("import"-strategy of reverse engineering). A practical example in this context is the described effort by Real Networks to reverse-engineer Apple's DRM system FairPlay. ${ }^{71}$

- Second, reverse engineering can be used as a tool to establish interoperability by facilitating the use of digital files intended to work only within 
a closed DRM ecosystem of a third party on other devices or services (“export"-strategy of reverse engineering). For example, Double Twist Ventures, a company run by Jon Johansen, reverse-engineered Apple's DRM system and announced that it intended to grant licenses that would allow devices other than the iPod to play iTunes content. ${ }^{72}$

As discussed above, the legality of reverse engineering to establish DRM interoperability - or at least certain forms of it (e.g. software-data-interoperability) - is uncertain under national anti-circumvention and copyright laws and usually also prohibited by the provider's license agreements or terms of services. Further, the lawfulness of reverse engineering in the DRM space depends on the particular method that is been used; often clearly in the problem zone are "export"-strategies. ${ }^{73}$

Applying the normative criteria outlined above, one might tentatively assess reverse engineering as an approach to DRM interoperability as follows:

- Reverse engineering is a bottom-up approach to interoperability. There is a high probability that the reverse engineer, if it is a commercial entity (consider, e.g., Real Networks), knows about the state of technology, consumer needs, the product and service markets, business models, etc. Thus, reverse engineering is characterized, in our view, by a high degree of permeability.

- Depending on the factual circumstances, reverse engineering can significantly improve interoperability among DRM systems. This holds true, for instance, if the market leader's DRM system is successfully reverseengineered. However, the "Harmony" example and Apple's response also demonstrate that such an approach may only work short-term, because the DRM provider has the possibility to update its DRM scheme continuously. In sum, reverse engineering tends to range at the lower end of an effectiveness scale.

- Viewed from the costs involved to achieve a higher level of DRM interoperability, reverse engineering seems comparatively cost-efficient. 
However, additional costs may be involved if this approach is used to maintain interoperability among competing platforms under the scenario just described (“arm's race”-situation). Furthermore, reverse engineers might face considerable legal costs under current law because reverse engineering might be illegal under the applicable law.

- As a bottom-up approach, reverse engineering is clearly a strategy that preserves high degrees of flexibility. It is hard to see how it would foreclose technological development.

- Reverse engineering may be seen as an approach that enhances competition and innovation in several respects. First, it might level the playing field, thus lowering the market entry barriers for new players. Second, it might trigger product or service innovation on the part of the provider of the product or service that has been reverse engineered. Third, reverse engineering can itself be seen as an innovative activity, leading to new applications and products that will compete on the market.

\subsubsection{IP Licensing}

The term IP licensing is used here in a broad sense to generically describe all approaches to DRM inoperability that are based on access to technology or technical specifications, including associated IP rights such as patents, copyright, trademarks, and the like, that is provided consensually. Thus, IP licensing has many different forms and faces. Often, licensing is also part of approaches that, for analytical purposes, are treated under a separate heading, such as the unilateral design of interoperable products or even standardization efforts. In any event, both the terms and conditions of a licensing agreement and, accordingly, their impact on the level of interoperability may vary significantly along at least three dimensions:

- Scope: The licensing agreement specifies the breadth of the rights that are granted. Obviously, the scope of the license might vary considerably. A license, for example, may allow a device manufacturer to develop products that fully support the functionalities of a DRM system. Alternatively, the license might only grant access to parts of the DRM system so that, for instance, the device manufacturer is not empowered to use certain special features supported by the system. 
- Compensation: Licensees often have to pay a licensing fee to access the licensor's DRM technology. However, there are also circumstances in which the licensee does not have to pay a fee but to give something else (e.g. another license in the case of cross-licensing) in return.

- Exclusivity: Licensing agreements may also differ in terms of the nature and number of contracting parties. For example, access to a given piece of DRM technology can be granted on an exclusive basis to one partner only (e.g. Motorola in the case of Apple's FairPlay), or to multiple partners (e.g. Microsoft's partners in the PlaysForSure initiative).

In the past few years, different types of licenses have been granted in the DRM music space that contributed in one way or another to DRM interoperability. Based on the characteristics of the licensor, one might group the examples for illustrative purposes as follows:

- Single companies that licensed their DRM technology: Microsoft, for example, has made its Windows Media DRM available for online stores such as Napster, Wal-Mart and Real's Rhapsody ToGo Service, and device manufacturers, including SanDisk. As noted, Microsoft pursued an open licensing strategy in order to encourage greater usage of the Windows Media Player jukebox and get a multitude of users of digital entertainment to "gravitate" around its software.

- Licensing agreements as part of bilateral co-operations: Important licensing deals where parties grant each other access to DRM technology have also taken place between companies at different levels of the value chain. For example, Microsoft and Nokia established a bridge between the Microsoft Windows Media DRM and the OMA DRM for wireless devices in February 2005: On the one hand, Nokia builds support into its music-playing phones for the Windows Media DRM, thereby allowing a transfer of protected music files onto Nokia devices. On the other hand, the OMA DRM finds support in the Windows Media Player via a plug-in. This collaboration enables owners of certain Nokia phones to buy music in either a Windows Media DRM or OMA DRM-compliant store and play it on their phones, PCs and other devices supporting the Windows Media DRM system.

- Multi-player organization licensing of DRM technology: A recent example is the work of the Marlin group, representing consumer electronics 
manufacturers and aimed at creating a DRM system that works with devices from different vendors. Its first specification, released in May 2006, is available to anyone who signs an evaluation agreement. ${ }^{74} \mathrm{~A}$ second example is the Digital Media Project (DMP), an independent standards initiative that started in September 2003 and has so far released two specifications. ${ }^{75}$ In the related area of mobile content, an important initiative aiming at DRM interoperability is the Open Mobile Alliance's (OMA) DRM system (see above).

Given the many forms of IP licensing that are and may be used to contribute to higher levels DRM interoperability, it seems particularly difficult to make a general assessment of the approach's merits and demerits. However, the following tentative assessment characterizes at least some of the overall promises and limits:

- IP licensing tends to be very context-sensitive in the sense that both the licensor and the licensee will carefully take into account the current state of the DRM music ecosystem, including the state of technology and market development, existing and emerging business models, consumer needs, etc. Licensing thus tends to have a great degree of permeability.

- The effectiveness of a licensing approach toward DRM interoperability depends very much on the concrete licensing agreement. As noted, the general licensing policy on the one hand and the particular terms and conditions on the other hand will ultimately determine the contribution of a single licensing deal to a more interoperable online music ecosystem. Licensing fees may play a particularly important role. And, obviously, the effectiveness depends on the company's willingness to provide access in the first place $-\mathrm{a}$ feature that may limit the approach's overall promise given prominent cases of players (like Apple) who refuse to license their DRM technology or related patents (see above).

- IP licensing tends to be a cost-efficient way of increasing the level of DRM interoperability. Especially sophisticated and "streamlined" licensing procedures provided by the big players reduce transaction costs significantly. 
The administration of licenses and compliance issues might be significant, depending on the volume and complexity of the licensing practices, but probably does not lower the approach's overall cost efficiency.

- IP licensing, generally speaking, is a market-driven and therefore flexible approach, which, in principle, does not foreclose the development and adaptation of future technologies. This holds particularly true in situations where non-dominant companies are contracting. In cases of multiparty licensing and widespread adaptation of a particular proprietary technology (emergence of a "de facto standard"), however, the degrees of flexibility might decrease due to the "stickiness" of a particular technology (switching costs) and collective action problems.

- The impact of DRM licensing on competition and innovation depends again on the particular licensing policy of the key players and the respective terms and conditions. Licensing in a competitive market environment can be expected to foster innovation and competition, as Microsoft's PlaysForSure initiative illustrates. In contrast, licensing may eventually slow down innovation and competition in cases where a player with a de facto standard changes its licensing policy or uses it in an anticompetitive manner (e.g. by refusing to license the DRM technology to particular players on the market place). ${ }^{76}$

\subsubsection{Open Standards}

Standards are a collaborative approach towards higher levels of DRM interoperability. As noted, several types of standards exist. Often, three forms 
are distinguished: proprietary DRM standards such as Apple's FairPlay; de facto standards like, in some parts of the world, SDC (Secure Digital Container) DRM technology; and open standards. ${ }^{77}$ While we have discussed proprietary standards in previous sections, ${ }^{78}$ this paragraph now focuses on open standards. The opinions on how to define the term "open standard" vary greatly. ${ }^{79}$ The ITU-T, for instance, defines open standards as follows:

"'Open Standards' are standards made available to the general public and are developed (or approved) and maintained via a collaborative and consensus driven process. 'Open Standards' facilitate interoperability and data exchange among different products or services and are intended for widespread adoption." ${ }^{80}$

Some definitions and characterizations require that (a) open standards are approved by formalized committees that are open to participation by all parties and operate on a continuous basis, and (b) are made accessible to the public free of charge. ${ }^{81}$ The European High Level Group on Digital Rights Management uses the following definition:

"Open standards are prepared by open standards organizations with an open process, published objectives, Fair, Reasonable and Non Discriminatory (FRND) based licensing terms (applicable where patented technology is incorporated in a standard). Furthermore open standards provide publicly available technical specifications hence any implementer can utilise the standard." ${ }^{2}$

Open standards have recently gained much attention in the debates about inrealities of open standards: black, white, and the many shades of gray, in: Shane Greenstein and Victor Stango (eds.), Standards and Public Policy, Cambridge University Press 2007, pp. 87-122. 
teroperability ${ }^{83}$, especially in the context of open document formats like Open XML. ${ }^{84}$ An example of an open standard in the DRM space is the abovementioned Open Digital Rights Language (ODRL) initiative, which seeks to provide an open and free standard for the semantics of DRM systems. ${ }^{85}$ This initiative meets even the narrow interpretation of the open standards concept. As noted, ODRL faces legal challenges because ContentGuard, the company that developed XrML, claims that ODRL infringes its patents.

Open standards are often perceived as the preferred way to achieve DRM interoperability. The above-mentioned High Level Group on DRM, for instance, stated in its final report that "[ $t]$ here is wide consensus that open standards offers [sic] the best realistic possibility for true cross-platform interoperability of services and devices from multiple providers, conducive to achievement of true user convenience and thereby mass market acceptance of DRM enabled services." 86

- As voluntary, multi-party, and market-driven initiatives, open DRM projects certainly take into account the current state of the DRM ecosystem. Thus they can be seen as the industry's response to the current state of market development, technology, business models, and (last but not least) customers' needs. In that regard, open standards represent a type of approach to interoperability with high degrees of permeability.

- Open standards have the potential to be very powerful mechanisms for achieving high degrees of DRM interoperability among the systems and applications of a large field of market players. However, there are also limitations. First, these initiatives represent a purely voluntary effort. Companies that decline to join the initiative but hold a patent in the area 
(i.e., a submarine patent or known blocking patent) can damage or even destroy the open standard. ${ }^{87}$ Second, an open standards-based approach may come under pressure once the interoperable DRM system is broken and the technology moves ahead to another model. ${ }^{88}$

- Standard-setting processes are usually complex and relatively expensive. Compared to unilateral or bilateral approaches to DRM interoperability, open standards are likely to absorb a greater amount of resources and management attention and are in this regard less cost-efficient. Especially the negotiation and coordination efforts may be costly, depending on the number of collaborators and their respective incentive structures. If a standard is flawed, it can be a significant setback for an entire technology area. For instance, the Secure Digital Music Initiative (SDMI) was a forum in the late 1990s including major record labels and technology companies that attempted to construct a "bulletproof" system to provide consumers with easy access to music while preventing piracy. When SDMI issued a challenge to the Internet community to attempt to break its encryption, a team led by Ed Felten at Princeton demonstrated that the entire premise of SDMI's technology was faulty. Since then, DRM technologies in music have developed almost exclusively on the "unilateral" model and not through any consensus in the industry. If SDMI had succeeded, the DRM sector would undoubtedly be more interoperable than it is today. Given that it failed, though, nobody has built sufficient momentum to develop any new standard-setting process.

- Open standards may provide a lesser degree of flexibility with regard to technological change than other approaches. Standard setting is a timeconsuming process. Even if this process is open and transparent, a standard is by definition a snapshot of the state of the art at a particular point in time and may even "freeze" a particular state of technology for a period of time. ${ }^{89}$ Further, it is likely that open standards, like other highly 
collaborative approaches to DRM interoperability, create some sort of "stickiness" the greater their acceptance among the stakeholders. ${ }^{90}$

- By providing access to the technology, its specifications, and the associated rights on the basis of a reasonable and non-discriminatory license (RAND) - with or without monetary compensation - open standards tend to reduce market barriers for new entrants and foster the development of new, interoperable products and services which, in turn, will satisfy consumers and lead to market growth. However, it should be also noted that standards consortiums may in certain constellations manipulate the standard-setting process in order to achieve anticompetitive ends. ${ }^{91}$

\subsubsection{Selected regulation-based approaches}

\subsubsection{Mandating Standards}

Another possible approach is that governmental authorities mandate the adoption of an interoperable standard on the part of industry players. Notably, this approach could take different forms. On the one hand, a government could unilaterally determine the standard, perhaps following an internal review and assessment of existing standards. On the other hand, government could merely set a timetable for the establishment and implementation of a common standard, but leave it to industry players to determine what that standard should be. Between these two poles, all manner of hybrid approaches are possible, where government enters into a dialogue with industry players. In such scenarios, government would be an active participant in the determination of the standard, but would also facilitate the input of industry players.

Here, we present two examples where governments have selected a standard to be adopted by industry:

- In the United States, the Federal Communications Commission decided to largely adopt standards developed by the Advanced Television Systems 
Committee for implementation in digital television. ${ }^{92}$ These standards incorporated the eight level vestigial side band (8-VSB) method for television modulation. ${ }^{93}$ The adoption of this modulation method was the result of studies conducted by a special advisory group formed within the FCC. ${ }^{94}$ These studies, however, were "supported by the work of hundreds of industry technical experts." 95 Following the formal adoption of the modulation method, the FCC received requests from private industry players to allow alternative methods. ${ }^{96}$ The FCC rejected these proposals, largely based on a study conducted by a group of private broadcasters that the Commission took as an indication that the industry widely preferred not to add the proposed alternative. ${ }^{97}$

- In the United Kingdom, the Crown government recognized that the realization of its e-Government initiatives would require the interoperability of various government programs. The e-Government Unit of the Cabinet Office therefore developed an e-Government Interoperability Framework (e-GIF), which “sets out the government's technical policies and specifications for achieving interoperability and Information and Communication Technology (ICT) systems coherence across the public sector." 98 In developing technical standards for interoperability, however, the e-Government Unit largely adopted prevailing, common Internet

Technical Research Branch, Laboratory Division, Office of Engineering and Technology, Federal Communications Commission, A STUDY OF ATSC (8-VSB) DTV COVERAGE IN WASHINGTON, DC, AND GENERATIONAL CHANGES IN DTV RECEIVER PERFORMANCE (April 9, 2001), p. 2-3, available at http://www.fcc.gov/Bureaus/Engineering_Technology/Reports/oetrpt4901.pdf.

See REPORT AND ORDER AND FURTHER NOTICE OF PROPOSED RULE MAKING, In the Matter of Review of the Commission's Rules and Policies Affecting the Conversion To Digital Television, MM Docket No. 00-39, FCC-01-24 (January 19, 2001), p. 32, available at http://www.fcc.gov/Bureaus/Mass_Media/Orders/2001/fcc01024.pdf. 
and World Wide Web standards. ${ }^{99}$ They also chose to adopt XML and XSL for data integration and management and developed an open discussion forum between the public sector and industry for the discursive development of common XML schemas for use in the public sector. ${ }^{100}$ In this manner, the e-Government unit aimed to combine standards that were widely accepted in the marketplace with the ongoing development of implementation strategies supported by industry input. ${ }^{101}$

A government mandated approach is generally the least popular among industry players. Notably, neither example represents a wholly top-down approach to the development of standards on the part of government. This is most likely due to perceived drawbacks in permitting government to establish standards for the industry, as well as a desire to facilitate democratic processes.

- There is a perception that governments are ill-equipped to determine on their own what existing or potential standards represent the best option. ${ }^{102}$ Additionally, critics fear that government selection of standards too easily falls prey to the influence of private interests. ${ }^{103}$ However, the government could mandate a standard that is developed by market participants, thus reinforcing a consensus and achieving significant permeability. To the extent that government attempts to independently develop or assess a standard, a government-mandated approach may not hold much promise of achieving permeability.

- On the other hand, government mandated interoperability can establish an interoperable solution where market forces do not prompt industry players to do so. As opposed to reverse engineering, the government mandated approach would establish a single standard for all industry players across the board as soon as a standard is adopted. Therefore, the effectiveness of this approach is particularly high. Where the government attempts to assess the best solution on its own, however, the process of 
implementation is likely to be notably slower than an approach which relies on industry to find the interoperable standard.

- Yet, the traditional government-mandated approach would not present any flexibility, since the government is not the best party to gauge market requirements and cannot adapt to changes in market conditions in an efficient manner. However, a recursive approach such as that taken by the UK government does offer notable flexibility.

- As for cost efficiency, a government-mandated approach is likely to perform poorly, since it will rely on government enforcement to ensure the standard is adhered to.

- The effects of a government-mandated DRM interoperability standard on competition and innovation remain uncertain. While a common standard may positively affect certain forms of competition within the online music market by leveling the playing field, it is likely to set negative incentives for the further development of proprietary technologies that, under a market-based scenario, may have the promise either to be widely licensed or become a de facto standard.

\subsubsection{Disclosure of interoperability information}

Another approach for achieving higher levels of DRM interoperability by regulatory means is to mandate the disclosure of information that is essential to build interoperable systems and applications. This approach has been taken by the French legislature, which made significant modifications to the French IP Code in August 2006. ${ }^{104}$ According to the current law (as amended), DRM schemes are not allowed to prevent effective interoperability. The IP code does not provide a definition of the term interoperability, but leaves it to a newly created regulatory authority for technical measures "to ensure that DRMs, 'because of lack of interoperability, do not create, in the use of a work, additional and independent limitations to those expressly chosen by the right-holder." ${ }^{105}$ According to French law, software publishers, manufacturers of technical systems, and service providers can contact the regulatory 
body in cases where the DRM supplier refuses to give access to interoperability information. The authority has to decide within two months whether the demand is to be rejected or the disclosure of the interoperability information is to be compelled through an injunction. The authority determines the scope and time-frame in which access has to be provided, and also sets the financial compensation that has to be paid to the disclosing party in return. It may also impose a severe financial penalty in the case of non-compliance with the injunction.

Mandatory disclosure of DRM interoperability information, as noted, is a recent phenomenon. Accordingly, there is very little experience with its practical implementation. However, based on the benchmarks we might make some reasonable hypotheses concerning the approach's pros and cons.

- It is unclear to what extent the permeability criterion, in this model, plays a role. Conceptually, one might imagine a scenario in which the administrative authority would take into account the market, product and service maturity as well as the state of technological development, business models, etc. when determining whether or not a DRM provider has to disclose interoperability information. Under French law, however, the language of the law itself does not indicate that such factors need to be considered.

- Arguably, the approach's effectiveness largely depends on the particular design of the relevant disclosure rules. Generally speaking, the impact on the interoperability level should not be overestimated, because the disclosure is limited in scope and concerns two parties only. In the French example, the effect is further limited by the fact that only technology companies may request the disclosure of interoperability information.

- As with other regulation-based approaches, mandated disclosure of information - depending on the design of the particular regulatory regime - may be associated with significant administrative costs. The creation and operation of a specialized administrative authority like in France is illustrative in this respect. Despite the lack of any data about the exact administrative costs, it remains uncertain whether this approach to DRM interoperability is more cost efficient than its alternatives. 
- Disclosure of interoperability information is unlikely to run the risk of creating any kind of lock-in or preventing the adoption of more advanced DRM technologies.

- It is currently highly contested whether the approach taken by the French parliament will ultimately strengthen competition and foster innovation. On the one hand, the approach prevents competitors from leveraging a refusal to license in an anti-competitive way, thereby enabling the creation of new and interoperable products and services in situations where licenses would otherwise not be granted. On the other hand, such a legal regime may disincentivize up-front investments in new DRM technologies in the first place, especially if the administrative authority would set compensation rates at relatively low amounts.

\subsubsection{Transparency rules, labeling requirements}

Traditional economics suggests that the DRM-protected music market works well when the different parties to the various transactions (e.g. purchase of a song on iTunes, or buying a Zune player) are informed of the price and qualities of the commodity or service they are contracting for. ${ }^{106}$ In the case of DRM, the characteristics of the commodities being traded cannot easily be assessed through inspection. Typically, they fully reveal their qualities (e.g. levels of interoperability among various devices and services) only upon use. For this type of experience good, a problem arises when the provider is better informed than its contracting partner and can take advantage of this informational asymmetry. One traditional strategy for dealing with this problem is to mandate the disclosure of information about the product or service quality. For instance, after Sony BMG DRM practices were publicized, United States regulators entered into consent decrees with Sony BMG mandating that it label copy-protected CDs to show what was and was not permitted, among other things. ${ }^{107}$ In the DRM space, consumer protection authorities, as noted before, have argued that providers of digital music should indicate whether 
the content is protected by a DRM system, what usage restrictions apply, and on what devices the work cannot be played. ${ }^{108} \mathrm{~A}$ more comprehensive transparency regime aimed at improving market efficiency would oblige all vendors of digital music not only to list usage restrictions, but also to provide a logo of the DRM software they apply (labeling). In addition, device manufacturers would be required to label their devices with the logos of the DRM software they support. Thus, for instance, Apple would have to design a logo for its FairPlay DRM and feature the logo on the iTunes Store as well as on iPod boxes, or to put it on the back of the devices. Consumer advocates maintain that consumers would then be better positioned to express their interoperability preferences by "voting with their wallets."

What are the promises and limitations of such a relatively indirect approach according to the previously defined benchmarks?

- The permeability criterion is not a feasible one to assess this particular approach. It may play a certain role in that legislators or regulators would consider the market developments, state of technology, etc. before mandating the disclosure of information about the interoperability quality of the respective platforms and devices.

- The approach's effectiveness is very difficult to determine. As noted, labeling requirements and the like would contribute to increased levels of DRM interoperability in indirect ways. They would almost certainly make consumers more knowledgeable, enabling them to express their preferences about DRM and interoperability through purchasing decisions. Much would depend on the actual design of the labeling provisions (inherent threat of information overload). In any event, information about the varying degrees of interoperation across platforms and devices would most likely support the emergence of a market for DRM interoperability.

- Information disclosure, including labeling, is obviously associated with costs, particularly monitoring and enforcement costs. In any event, an information-based approach to interoperability is likely to be more cost efficient than the regulatory approaches sketched before. 
- There are no signs that labels and other forms of product and service interoperability information would be conflict with the development and adaptation of new DRM technologies in the future.

- To the extent that labeling would reduce existing information asymmetries among market participants, it would clearly enhance the functioning of the online music market. The approach would also increase users' trust in online stores and digital distribution of content more generally. This, in turn, may result in market growth, which attracts new competitors providing innovative products and services.

\subsubsection{Conclusion}

While any benchmarking of different approaches towards DRM interoperability would need a detailed and case-specific investigation, the preceding evaluation may serve at least to flag some trends with regard to potential benefits and drawbacks of the different approaches examined. Within the portrayed private actor-driven approaches, IP licensing of DRM technology appears as a necessary, but likely not sufficient condition to achieve a high degree of interoperability. If combined with other approaches such as open standards, however, licensing appears to become a crucial element in the mix - also (but not only) due to its positive overall impact on competition and innovation (leaving potential anti-competitive behavior aside). As far as regulation-based approaches are concerned, we caution both against the use of a government-mandated standards approach as well as mandatory DRM information disclosure requirements imposed by legislation. While the discussion of the particular merits and demerits of both approaches depend on the envisioned implementation of the respective approach, it seems appropriate to conclude that especially a mandatory standards approach performs poorly under several of the proposed evaluation criteria. However, we also conclude that the government can (and actually does) play an important role in the DRM-protected music interoperability ecosystem in that it adjusts existing legal frameworks to create incentives for market players to achieve higher levels of interoperability. Such strategies include labeling requirements aimed at reducing information asymmetries between DRM providers and consumers, the explicit permission of reverse-engineering in copyright and anti-circumvention legislation, and governmental promotion of the development of industry standards for DRM by providing frameworks for cooperation. 
Based on the merits and demerits of the six approaches, we conclude that probably the most promising strategy towards higher and sustainable degrees of DRM interoperability would consist of a blended approach where private-sector efforts would interplay with supplementing, regulation-based approaches (e.g., reverse-engineering exceptions and transparency requirements, among others). In this respect, further research might explore how the different approaches could work together and compensate their respective weaknesses while amplifying the respective strengths 


\section{SUMMARY}

1. In this case study, aimed at exploring the current state and possible future of DRM-protected music interoperability and its interplay with competition and innovation, we developed a holistic, non-technical definition of DRM interoperability by circumscribing it as the perceived notion of the proper functioning of the relevant elements of two or more entities that facilitate access to and use of digital content. At the core of the definition is the relative ability of different systems, applications or components - usually provided by multiple vendors - to work together in a manner that is satisfactory to the relevant users of the system, application, or component.

2. Understanding DRM interoperability as a continuum along a spectrum, interoperability, according to the proposed working definition, would mean different things to different stakeholders, for example:

- DRM interoperability from the user's perspective means that she can flexibly choose among different services that offer DRM-protected content, which in turn can be used with different applications or on different devices.

- From the angle of a content provider, DRM interoperability means that content and rights can be "cleared" once and distributed over the most efficient distribution channel, without being locked-in to a gatekeeperlike distribution channel. 
- From the content distributors perspective, DRM interoperability ensures that its technology choice does not affect the utility of its service to users, as the delivered content might be played by any application and device.

- Interoperability for the vendor means that her products work with different services, or (more generally) that one system's component can be replaced by a component from another vendor.

3. DRM interoperability issues have emerged both in the context of the offline and online distribution of music. In the case of DRM-protected online music, many observers - including lawmakers and agencies - have diagnosed relatively low degrees of interoperability. Several major players in the online music space have decided to keep their DRM ecosystems and platforms closed, including Apple (iTunes) and Microsoft in the case of Zune/Zune Marketplace. At the same time, however, alternative developments have taken place most recently. First, online music services have emerged that allow permanent music downloads in an unprotected format. Second, EMI recently announced that it would license its music catalog DRM-free and at higher sound quality to various online music stores.

4. Digital music distribution is a complex system. Thus, several factors shape the state of play of DRM music interoperability. Among them is technological complexity, reflected in various technical approaches that have been proposed to achieve interoperability (including, for instance, process and architecture-oriented approaches). As a case in point, we used the example of rights expression language, including RELs and initiatives, respectively, like XrML, ODRL, or Coral, to illustrate that complexity. Further, we identified the dynamic incentive structures of important stakeholders as another important factor that shapes the DRM interoperability ecosystem. Using the Apple's iTunes as a case study and tracking the licensing policy of Microsoft in the DRM music space, we concluded that DRM interoperability strategies might not only vary within one (relatively homogenous) group of stakeholders, but that there are also situations in which key players change their (liberal) interoperability strategy despite consumer demands to the contrary. We discussed the bi-directional role of law as another important factor in the DRM interoperability environment. Software patents and anti-circumvention legislation might be constraints on interoperability, while competition law and consumer protection laws may enable an increased level of interoperability. 
5. In this case study, we also outlined some of the merits and demerits generally associated with high levels of DRM interoperability, paying particular attention to its impact on innovation and competition in e-environments. Conventional economic analysis suggested a "non liquet" from the two perspectives just mentioned. Lacking empirical evidence and facing manifold interrelations among market structure, intellectual property rights, and the expectations of different stakeholders, we concluded that there is need for a case-by-case economic analysis of the particular DRM interoperability issues up for discussion - probably analogous to the sort used in competition law cases. However, we have also argued that normative arguments tip the balance towards interoperability as a general policy goal. We considered autonomy, access, diversity, and openness to be democratic values worth supporting. In contrast, our discussion of the potential drawbacks of increased levels of DRM interoperability, as suggested by some market players, led to the conclusion that the possible downsides - including security threats, privacy concerns and accessibility issues - do not outweigh the benefits of a highly interoperable DRM ecosystem.

6. The paper further outlined and mapped several approaches that can be used in practice to aim for a higher degree of DRM interoperability. Acknowledging that other approaches exist, we listed approaches such as unilateral design, reverse engineering, IP licensing, technical collaboration, standards, and regulatory approaches. We then characterized and evaluated three private actor-driven approaches (reverse engineering, IP licensing, and open standard initiatives) and three regulation-based strategies (mandating standards, disclosure of interoperability information, transparency for consumers) in greater detail. Acknowledging that any benchmarking would entail a detailed caseby-case analysis, we identified some «trends» with regard to potential strength and weaknesses of the selected approaches by use of five evaluation criteria (permeability, effectiveness, cost efficiency, flexibility, and stimulating power with regard to competition and innovation). We concluded that a blended approach where private-sector initiatives would interplay with supplementing, regulation-based approaches is likely to constitute the most promising strategy towards higher and sustainable degrees of DRM interoperability. 
